\title{
RESEARCH REPORT KNOWLEDGE AND ATTITUDES RELATING TO CONDOMS ON THE PART OF AFRICAN HIGH SCHOOL CHILDREN AROUND JOHANNESBURG.
}

\author{
Gidon Frame, Paulo Ferrinho, Clive Evian
}

\section{INTRODUCTION}

There have been very few reported studies on the use and acceptance of condoms amongst South Africa's black population.

In a study in Cape Town on 377 Xhosa speaking township high school students researchers found that $75 \%$ of the students had sexual intercourse previously. This study highlighted severe misconceptions and misinformation about AIDS in general. Of those students who reported previous sexual intercourse, only $11 \%$ had ever used a condom, but $39 \%$ of students said they would use condoms in future. Knowledge about the correct use of condoms and the poor acceptability of condoms were further emphasized as being problematic (Matthews, Kuhn \& Metcalf 1990). Evian et al $(1990)$ in a qualitative study on 35 literate black adults, divided in six groups of either male or female respondents in the Johannesburg area, found that condoms were rarely used, that they were not used to prevent sexually transmitted diseases and that their availability and acceptability was minimal. Furthermore the use of condoms in this target group was felt to be problematic in that if one of the sexual partners suggested using a condom this would imply that one of the partners has a sexually transmitted disease which would create distrust and tension in the relationship. This last factor was also a finding in the Zimbabwean study discussed below and for this reason resulted in condoms being rejected. A study involving 429 mineworkers, selected systematically from 4 mines on the Witwaterstand, reported that the workers said they use condoms in approximately $25 \%$ of sexual encounters with "girlfriends" and $66 \%$ had never used condoms (Ijsselmuiden, Padayachee \& Mashaba 1990). In an extensive review of data on condom use in Sub-Sahara Africa, a wide range in womens knowledge of condoms was found, but less than $1 \%$ of the women sampled used condoms (Goldberg et al 1989). Mbizvo \& Adamchat (1989) in a Zimbabwean study reported that only $35,7 \%$ of sexually active men had ever used

\begin{abstract}
Senior high school children completed a self-administered questionnaire on sexual activity, knowledge of family planning methods, condoms and use of condoms. The study highlighted some useful and interesting information though its value is limited by a poor response rate.
\end{abstract}

The results suggest that at least $50 \%$ of the scholars are sexually active, but only about 20\% reported sexual intercourse during the month preceding the survey. This small group reports more than 1 sexual partner and unprotected sexual intercourse in over $50 \%$ of the cases. Knowledge of condoms was poor and a number of factors relating to resistance to condoms are identified. These must be addressed by a combination of social marketing and educational strategies.

The most important finding is that half of the children were still not sexually active. Education programmes therefore should support the development of safe and responsible sexual lifestyles.

condoms and that only $4,9 \%$ currently would use one. This study found 100 , that the failure to use condoms was related more to inadequate information, lack of knowledge and general fears on sexual performance than to religious or cultural factors. The control of AIDS centres around keeping the number of sexual partners to a minimum and practising sex safely. The use of condoms is an important component of a safer sex life.

It is often said that the use of condoms commonly is resisted for cultural and other reasons. For the planning and implementation of condom distribution programmes it is essential to identify clearly the obstacles have to be overcome.

In this study we report and discuss the results of a survey on some aspects of sexual practices, knowledge and attitudes towards condoms amongst a group of scholars.

\section{POPULATION AND METHODS}

The study is descriptive. The study group consisted of senior African High School children (standard 9 and 10), from Johannesburg and surrounding urban areas who attended a weekend workshop on sexuality in March 1989. Data was collected using a structured questionnaire on sexuality, family planning, sexually transmitted diseases and ADDS.

The workshop facilitators, after instruction on the methods and purpose of the questionnaire, returned to their groups where they handed the questionnaires and collected them bouk before any instruction took place. The total number of attenders and questionnaires handed out was not recorded therefore it was not possible to calculate a response rate.

\section{RESULTS}

Of the total of 265 respondents no data on gender was available for $76(29 \%)$. For the remainder, $36 \%$ were males and $64 \%$ females. There were no data on age for $39(15 \%)$ of the children. Eighty seven percent of those for whom age was recorded, were in the age group 15 to 19 years, $10 \%$ were aged 20 to 24 years, $1 \%$ was 25 years old or over and another $1 \%$ was below 15 years.

When asked about previous sexual intercourse $44 \%$ (117) of the children did not respond to the question. Of the remaining 148 children, $50 \%$ reported previous sexual intercourse and of these $22 \%$ reported sexual intercourse during the month preceding the survey. 
Of the small group of 16 reporting sexual intercourse during the previous month, $47 \%$ reported 1 sexual partner, $21 \%$ reported 2 partners, $5 \%$ reported 3 partners, $11 \%$ reported 4 partners and $16 \%$ reported 5 partners or more. Fifty percent did not use any contraceptive methods, $11 \%$ used a condom, $11 \%$ were on a loop and $28 \%$ on an injectable.

Overall $11 \%$ of males and $23 \%$ of females did not know of any contraceptive methods. As shown in Table 1, males were more likely to know about condoms and females were more likely to know of other methods of contraception.

TABLE 1

Knowledge of Family Plenning according to the Gender of the Partner $(n=180)$

\begin{tabular}{|c|c|c|}
\hline METHOD & MALES & FEMALES \\
\hline Non & $7(11 \times)$ & $28(23 \times)$ \\
\hline Condom & $54(83 \%)$ & $45(396)$ \\
\hline Othor & $4(8 \%)$ & $44(386)$ \\
\hline
\end{tabular}

chi squere, $D F=2, p=0,000$

Seventy nine percent of respondents agreed with the statement "condoms prevent the spread of disease" (no data in 55 cases) and $82 \%$ agreed that "condoms prevent the spread of AJDS" (no data in 110 cases).

Table 2 shows that when stratified according to awareness of family planning methods, those not knowing of any methods were less likely to know that condoms can prevent the spread of AIDS. The data for males who had been sexually active during the month preceding the survey were analyzed for knowledge and attitudes to condoms. The group is small, composed of only 10 males. Four did not know how to use or where to get condoms and 3 felt they were too ensive. None of the males wished to have a cima but 2 felt that their partners were keen to have a baby. A further 6 felt shy or too embarrassed to use condoms, 5 felt it reduced pleasure and 9 felt that their partners disapproved of them.

TABLE II

Knowledge of Preventlon of Aide by Condome Stratlfied according to ewerenese of Femlly Planning Mothode $(n=151)$

\begin{tabular}{|c|c|c|}
\hline METHOD & \multicolumn{2}{|c|}{ CONDOMS PAEVENT AIDS } \\
\hline & Ye0 & no \\
\hline Nono & $13(62 \%)$ & $8(30 \%)$ \\
\hline Condom & $84(80 \%)$ & $14(14 \%)$ \\
\hline Other & $27(84 \%)$ & $5(18 \%)$ \\
\hline
\end{tabular}

chi squere. $D=2, p=0,033$

\section{DISCUSSION}

The data are of limited value because of the poor response rates and the difficult nature of the questions, but it nevertheless provides useful insights into behaviour and thoughts of young people. The results are very similar to those reported for high school children in Cape Town.

A significant proportion of the population studied was not yet sexually active. The sexually active do show a worrisome pattern of multiple sexual partners (53\%), unprotected coitus $(50 \%)$ and neglect of condom use. This is similar to data at the Alexandra Health Centre Service for patients with sexually transmitted diseases; $34 \%$ of these patients had more than one sexual partner (Frame, Ferrinho \& Phakathi 1991). This suggests that sexual behavioural patterns develop early in sexual life and that therefore young people are an important target for educational interventions.

The study suggests too, that females are more likely to be ignorant of contraceptive methods than males. Those ignorant about contraception are also more likely to ignore the fact that condoms prevent the spread of AIDS. It seems that greater exposure of young women to sex education and contraceptive methods would have an important role in the campaign against AIDS.

Significant proportions of sexually active males did not know where to get condoms, at what cost and how to use them. These problems may be successfully addressed by a social marketing strategy, together with strategies to increase the accessibility of condoms. (Population Services International 1989. Thesen 1990. Helizer-Allen 1990).

Resistance to condoms based on perceptions that they reduce sexual pleasure or that they are rejected by one of the partners and may cause embarrassment, are personal issues that require a more individualized educational approach.

There is little doubt that condom acceptability amongst all population groups in South Africa is generally low and this is expecially so amongst people from South Africa's low socio-economic communities. The availability of condoms needs to be addressed urgently. Condoms should be readily and easily available, at affordable costs at many different outlets such as shebeens, street vendors, pharmacies and hypermarkets. Educational programmes should emphasise the correct use of condoms and other methods of safe sexual practice. Political organizations need to play a role in depoliticizing the condom and promoting its use in South Africa. Finally, the state could make condoms available on a mass scale, at very low prices and investigate successful marketing strategies used elsewhere in Africa. The most important finding of this report may be that a significant proportion of the children studied were still not sexually active, their sexual behaviour was still not established and that they represent an ideal group for primary prevention of STD in general and AIDS in particular. Interventions should promore children's beliefs in themselves regarding their ability to perform health enhancing acrions. They should promote a sense of autonomy and mastery over one's own behaviour and environmental demands, thereby strengthening their ability to take decisions which will have a positive effect in their lifestyle and health. (Deci and Ryan 1980 Deci et al 1981. Harter 1981. Ryan, Connell \& Deci 1985).

\section{BIBLIOGRAPHY}

DECI EL, RYAN RM. The empirical exploration of intrinsic motivational processes. In Berkowitz L (ed) Advances in Experimental Social Psychology. New York: Academic Press, 1980.

DECI EL, SCHWARTZ A, SHEINMAN L, RYAN RM. An instrument to assess adults orientations towards control versus antonomy with children: reflections on intrinsic motivation and perceived competence. Journal of Educational Psychology 1981; 73: 642-650

EVIAN CR, IJSSELMUIDEN CB, PADAYACHEE GN, et al. Qualitative evaluation of an AIDS Health Education Poster. A rapid assessment method for health education materials. South African Medical Joumal 1990; 78: 517-520.

FRAME G, FERRINHO P, PHAKATHI G. Patients with sexually transmitted diseases at the Alexandra Health Centre and Universily Clinic. A review of one year data. South African Medical Journal 1991; (IN PRESS).

GOLDBERG HI, LEENC, OBERLE MW et al, Knowledge about condoms and their use in less developed countries during a period of rising AIDS prevalence. Bulletin of the World Health Organizarion 1989; 67: 85-91.

HARTER S. A new self-report scale of intrinsic versus extrinsic orientation in the classroom. Development Psychology 1981; 17 : 300-312.

HELITZER-ALLEN D. A Primer on Social Marketing. Development Communication Report (DCR) 1990/2, 69: 7.

IJSSELMUIDEN CB, PADAYACHEE GN, MASHABA W. Knowledge, beliefs, practices among black goldminers relating to the transmission of human immunodeficiency virus and other sexually transmitted diseases. South African Medical Journal 1990; 78: 520-523.

MATTHEWS C, KUHN L, METCALF CA, et al. Knowledge, attitudes and beliefs about ADS in township school students in Cape Town. South African Medical Journal 1990; 78: 511-516

MBIZVOMT, ADAMCHAKDJ. Condom use and acceptance: A survey of male Zimbabweans. Central African Joumal of Medicine 1989; 35: 519-523. 
POPULATION SERVICES INTERNATIONAL (PSI). Social Marketing and Mass Media AIDS Prevention Project in Zaire. PSI Annual Report 1989.

RYAN RM, CONNELL JP, DECI EL. A motivational analysis of self-determination and self-regulation in education. In: Ames C, Ames R (eds). Research on Motivation in Education, the Classroom Miliu; 2: 13-51. New York: Academic Press, 1985.

THESEN G. Social Marketing and Basic Education. Development Communication Report (DCR) 1990/2, 69: 6-10.
Gidon Frame $M B B C h, B S c$ Alexandra Heath Centre and University Clinic and Institute for Urban Primary Health Care

Paulo Ferrinho MBChB, DTM\&H, $M S c(M E D)$

Alcxandra Heath Centre and Universit Clinic and Institute for Urban Primary Health Care

Clive Evian MBBCh, MFGP, H DIPED AD Department of Community Health of the University of the Winwatersrand and Ciry Health Department, Johannesburg. 